\title{
Advanced solar assisted desiccant and evaporative cooling system equipped with wet heat exchangers
}

\author{
Pietro Finocchiaro*, Marco Beccali, Bettina Nocke \\ Dipartimento dell'Energia, Università degli Studi di Palermo, Via delle Scienze bld. 9, 90128 Palermo, Italy
}

Received 31 May 2011; received in revised form 15 September 2011; accepted 6 November 2011

Available online 2 December 2011

Communicated by: Associate Editor P. Gandhidasan

\begin{abstract}
This work concerns an innovative solar assisted desiccant and evaporative cooling (DEC) system for building air conditioning. In this system, air-to-air packaged wet heat exchangers are used to maximize the exploitation of the evaporative cooling potential associated with the exhaust air stream.

The thermodynamic cycle is first theoretically described, and then an example of a real application is shown.

The system presented is an experimental DEC system originally installed at the beginning of 2008 at the Solar Laboratory of the University of Palermo and recently modified and updated. These modifications have been implemented with the aim to foster some problems related to the conventional indirect evaporative process and to increase the overall performance of the process.

Different energy performance figures, such as thermal and electrical COP, are presented and discussed.

The obtained results are very positive, showing that DEC systems can benefit from the use of wet heat exchangers to efficiently cool the air stream after the adsorption process in the desiccant wheel without any change in moisture content.
\end{abstract}

(C) 2011 Elsevier Ltd. All rights reserved.

Keywords: Solar cooling; Desiccant evaporative cooling; Wet heat exchanger; Indirect evaporative cooling

\section{Introduction}

The Solar DEC technology is an interesting and fascinating solution for applications in building air conditioning. It is a thermally driven open cooling cycle based on evaporative cooling and adsorption processes. In a solar desiccant cooling cycle, solar energy is used to regenerate a desiccant material that dehumidifies moist air by vapor adsorption; the resulting dry and warm air is cooled in a sensible heat exchanger (usually rotating) and then in an (direct) evaporative cooler. By associating different elementary treatments in moist air (dehumidification, sensible cooling and evaporative cooling) both in the process and exhaust air, the technique uses water as a refrigerant and

\footnotetext{
* Corresponding author. Tel.: +39091238 61908; fax: +39 091484425. E-mail address: finocchiaro@dream.unipa.it (P. Finocchiaro).
}

mostly solar energy as driving heat. In a solar autonomous DEC system, electricity is only used in the auxiliaries, so the technique is environmentally friendly. If the pure DEC effect is not sufficient to guarantee indoor air conditions for the specific application, a hybrid DEC - conventional cooling cycle can be used by adding one or more traditional cooling coils connected with an electric water refrigerator to the standard DEC cycle (Henning, 2004).

In some recent studies, the energy performances of the DEC systems have been investigated, but a few cases have mentioned energy savings in comparison to a conventional air handling unit (AHU) (Bourdoukan et al., 2009; Rowe et al., 2010).

Monitoring results of the DEC system in the original configuration have been presented in previous publications by the same authors (Beccali et al., 2008, 2009). Monthly results were presented and elaborated according to a monitoring 


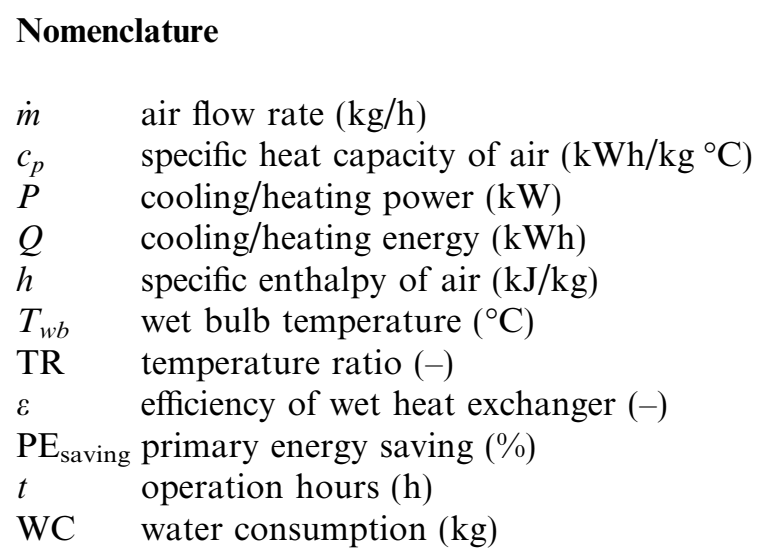

$r_{0} \quad$ heat of vaporization of water $(\mathrm{kWh} / \mathrm{kg})$

HX heat exchanger

$\mathrm{CC}$ cooling coil

$\mathrm{HC}$ heating coil

HU humidifier

DW desiccant wheel

AI air intake

AHU air handling unit

DEC desiccant evaporative cooling procedure developed in the framework of the International Energy Agency (IEA) Solar Heating and Cooling (SHC) Programme, Task 38 "Solar Air Conditioning and Refrigeration" (Sparber, 2008; Sparber et al., 2009).

This paper concerns an advanced DEC cycle concept and the modifications made to the existing experimental DEC plant to implement the new system configuration.

Summer meteorological conditions of the specific site according to the Italian climate database DBT of ENEA are $28.3{ }^{\circ} \mathrm{C}$ and $60 \%$ respectively as mean diurnal temperature and relative humidity for the time period of June, July, August and September. Peak values of $30{ }^{\circ} \mathrm{C}$ and $75 \%$ respectively for temperature and relative humidity are normally reached during summertime.

\section{Description of the components and thermodynamics}

The main innovation in the DEC process is the use of cross flow plate heat exchangers. These devices are commonly used in air conditioning systems for heat recovery purposes during the winter. When indirect evaporative cooling is used, the same heat exchangers can be used to efficiently cool the outside air during summer, wetting the channels of the exhaust air with water (Rey Martinez et al., 2004). In addition, this component can efficiently be integrated in a desiccant cooling cycle downstream of the adsorption process.

Other authors have already considered the application of wet surface heat exchangers for indirect evaporative cooling, but only in few cases has the coupling with DEC system been investigated (Jain and Dhar, 1995; Rowe et al., 2010).

The surface of secondary flow (return air from the building) air channels is wetted by water sprayed by nozzles, such that a water film evaporates into the cooling air and decreases the temperature of the heat exchange surface. Process air flowing in the primary airflow channels is cooled down due to the lower temperature surface of the separating wall of the heat exchangers (Fig. 1).

Some theoretical studies show that, due to the high values of water surface tension, the wall surface of cooling air passages cannot be completely wetted with spray water, which leads to a reduced mass transfer area for film evaporation (Chengqin and Yang, 2006; Guo and Zhao, 1998).

In Fig. 2, the thermodynamic processes of the primary air and secondary air are shown on a psychrometric chart. If the enthalpy related to the evaporating water on the secondary side of the heat exchanger and heat losses to the ambient are neglected, the following enthalpy balance can be written:

$\dot{m}_{1}\left(h_{11}-h_{12}\right)=\dot{m}_{2}\left(h_{22}-h_{21}\right)$

For an estimation of the energy performances of a wet heat exchanger, efficiencies and temperature ratios can be defined with the following formulas:

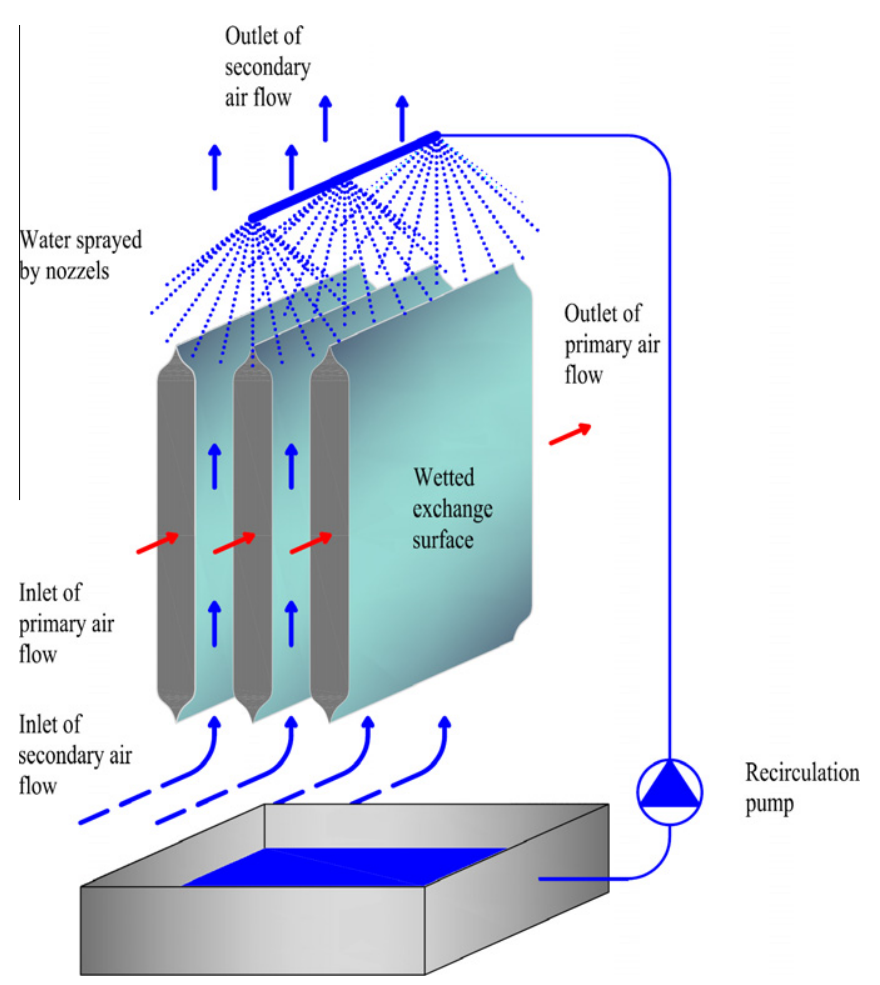

Fig. 1. Scheme of a packaged wet heat exchanger used for indirect cooling process. 


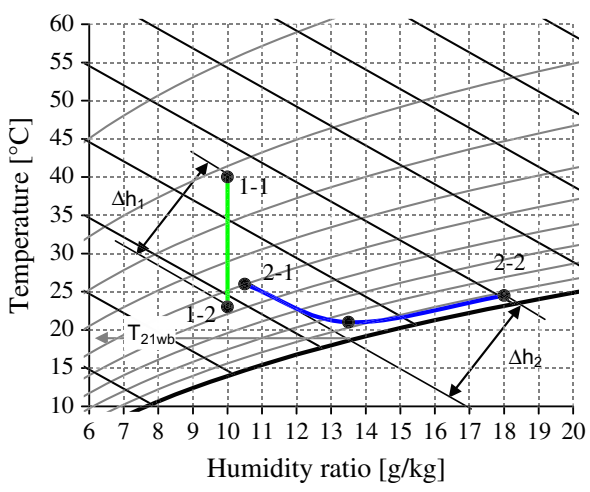

Fig. 2. Indirect evaporative cooling realized in a wet heat exchanger on the psychrometric chart - primary and secondary flows are marked with 1 and 2 , respectively.

$\varepsilon=\frac{P}{P_{\max }}=\frac{\dot{m}_{1} c_{p 1}\left(T_{11}-T_{12}\right)}{\min \left[\left(\dot{m}_{1} c_{p 1}\right),\left(\dot{m}_{2} c_{p 2}\right)\right]\left(T_{11}-T_{21 w b}\right)}[\%] ;$

$T R=\frac{\left(T_{11}-T_{12}\right)}{\left(T_{11}-T_{21 w b}\right)}(-)$

The temperature ratio and efficiency approximately coincide if mass flow rates on both sides of the heat exchanger are equal. As already mentioned, this component realizes a continuous humidification of the air during the heat exchange process, permitting to reach high heat transfer coefficients on the secondary side and consequently low values of the mean temperature of heat exchange surface. Therefore primary air can easily be cooled to temperatures even lower than of the entering secondary air because the secondary air status is kept close to the saturation line during the whole heat exchange process.

\section{System layout and modification of the original DEC configuration}

The layout of the original DEC system was a hybrid configuration with two additional auxiliary cooling coils fed by a conventional vapor compression chiller integrated in the DEC air handling cycle (Fig. 3). One coil is used for pre-dehumidification of the outside air stream; the other coil controls the air temperature if the desired supply temperature cannot be reached through indirect evaporative cooling alone. Another specific feature of the system is the use of part of the heat rejected by the refrigerator condenser to preheat regeneration airflow (see Fig. 4).

In the paper mentioned above (Beccali et al., 2008), the system layout and its peculiarities are fully described, and several monitoring results are presented and discussed. As reported in detail, the system showed globally regular operation and good energy performance during the monitoring phase. A primary energy saving of about $50 \%$ as a mean seasonal value for the cooling operation was calculated. On the other side, some weak points related to the energy performances of the system were found, such as the following:
- High need of an auxiliary energy source; approximately $50 \%$ of the total cooling energy delivered by the AHU is produced by the electric water refrigerator.

- Carry-over of water vapor from the return to the process air side inside of the rotating heat exchanger, which can be caused by air leakages across the sealing devices but also by dust deposition on the internal surface of the channels in the heat exchanger. Like an adsorbent material, dust can adsorb humidity that can be thus transferred form the return to the supply side. It was found that moisture carry-over, reducing the dehumidification potential of the desiccant unit, may affect the energy performance of the system, leading to a greater use of the auxiliary cooling coils.

- Low contribution to the sensible cooling load of the building; supply temperatures registered at the outlet of the rotating sensible heat exchanger were never under $26{ }^{\circ} \mathrm{C}$.

Fore these reasons system was recently modified and the main changes introduced can be summarized in the following points:

- With the aim to increase the cooling effect due to water evaporation in the return airflow rate and to eliminate the moisture carryover that previously occurred in the rotative heat exchanger, the sensible heat exchanger was replaced with two plate heat exchangers displaced in series for a continuous humidification of the secondary air flow. The new components installed consist of two cross flow flat plate heat exchangers, a set of spray nozzles, a basin and a recirculation pump. The spray nozzles used operate with low water pressure and do not require special maintenance. Thus return air is humidified in two steps before leaving the AHU after the heat exchange with the supply air stream.

- The return humidifier was eliminated. Some initial comparative tests on the performance of the system with and without the first stage humidification package have shown that the return air is sufficiently humidified by the wetted surface inside the heat exchanger.

- No humidifier on the supply side is used, since the outside air humidity ratio is normally quite high in the summertime. Actually, for the specific site, air humidity ratio at outlet of the desiccant wheel is seldom much lower than the desired value. Therefore the use of a supply humidifier would occur very seldom.

- Desiccant wheel is regenerated by fresh air, which is heated by the two heating coils. It implies the use of an additional fan but, on the other hand, the regeneration airflow can be reduced.

- No by-pass is used anymore to limit solar heat consumption for the regeneration and to reduce pressure drops during the wintertime. The decision to avoid the by-pass across the desiccant rotor and the use of outside air for the regeneration of the desiccant rotor was aimed to improve the thermal $\mathrm{COP}$ and to reduce electricity 


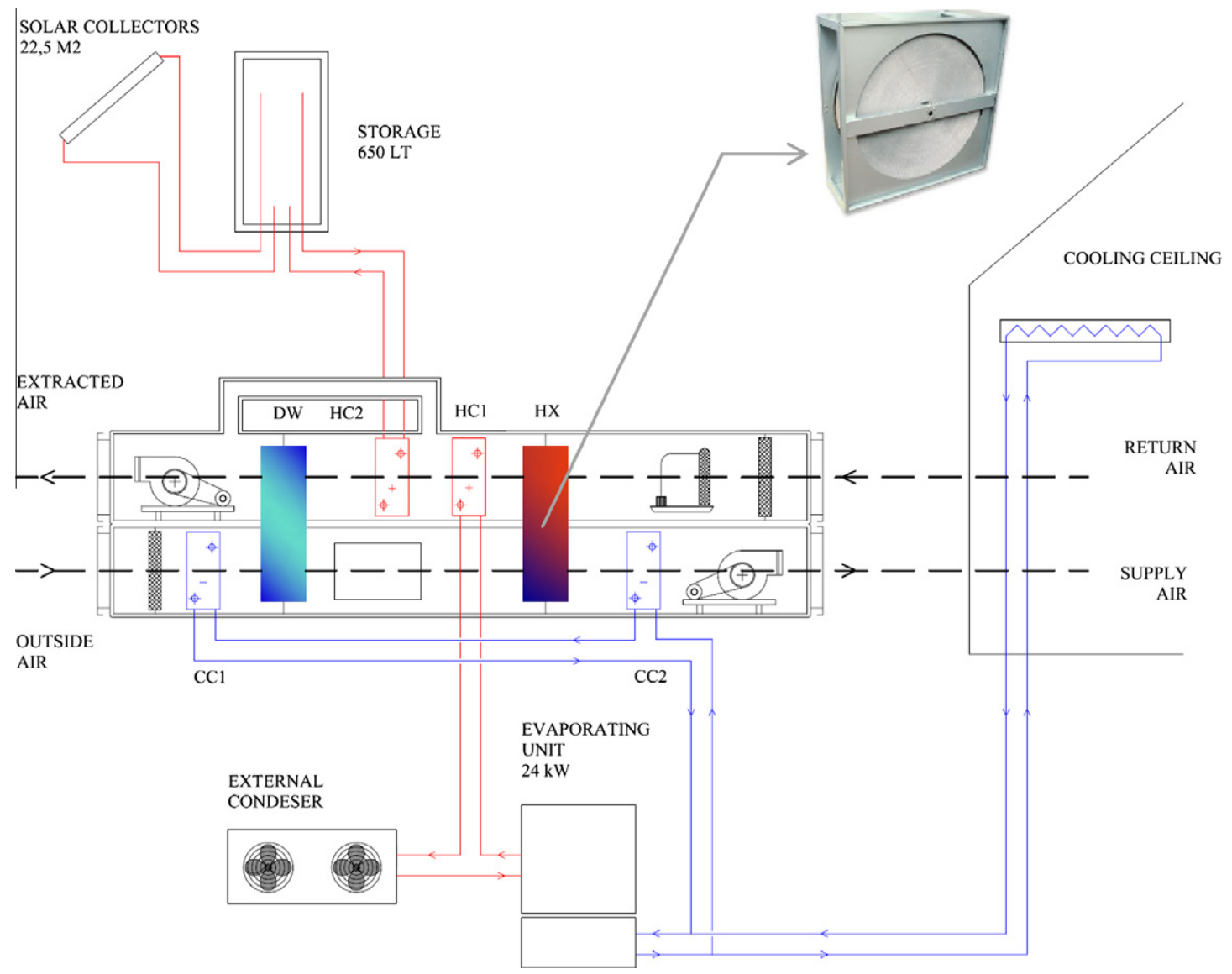

Fig. 3. Layout of the previous DEC system.

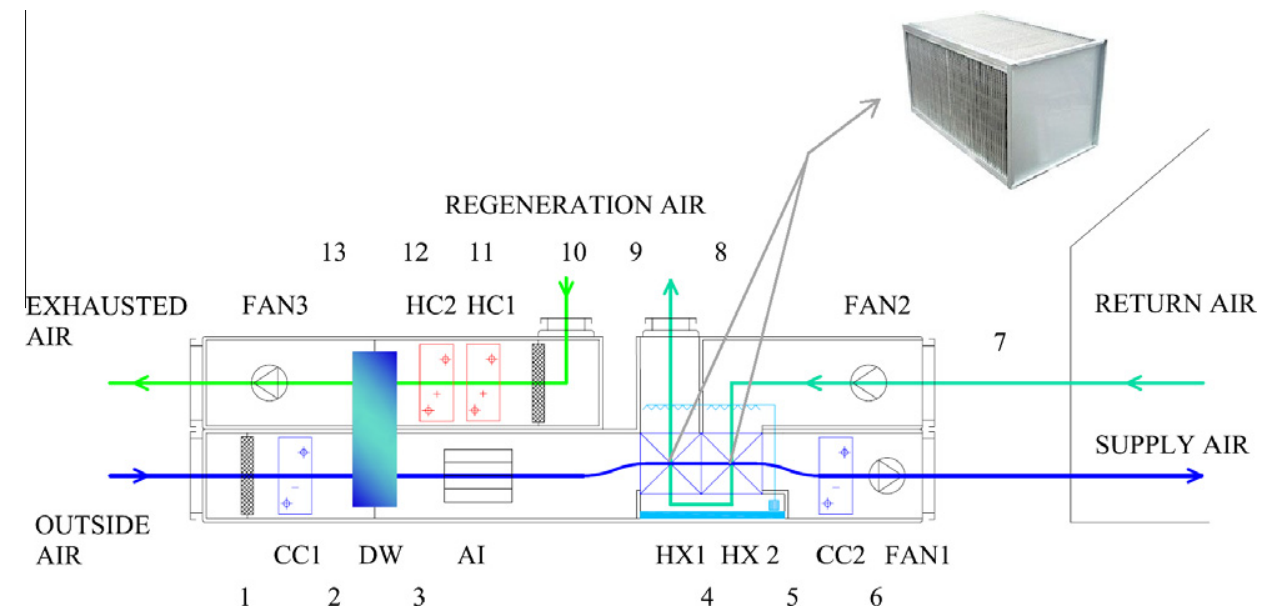

Fig. 4. Layout of the DEC AHU after the modifications are done.

consumption of the regeneration fan. Regeneration flow rate can now be modulated independently of the return air flow.

In Table 1 principal design data of the system are listed.
The air handling on the psychrometric chart is shown for typical summer operation conditions in Fig. 5. The total cooling power of both wet heat exchangers is the enthalpy difference between points 3 and 5 . It can be noted that no additional cooling coil is used to reach the supply temperature of $22{ }^{\circ} \mathrm{C}$. 
Table 1

Design data of main components installed in the system.

\begin{tabular}{|c|c|c|c|c|}
\hline \multirow[t]{2}{*}{ Component } & \multirow[t]{2}{*}{ Description } & \multirow[t]{2}{*}{ Project data } & \multicolumn{2}{|c|}{ Configuration } \\
\hline & & & Previous & New \\
\hline \multicolumn{5}{|l|}{ Air handling unit of $1250 \mathrm{~m}^{3} / \mathrm{h}$} \\
\hline \multirow[t]{7}{*}{ Desiccant wheel } & Silicagel & & & \\
\hline & $D=700 \mathrm{~mm}, W=200 \mathrm{~mm}$ & $T_{\text {ext }}=30^{\circ} \mathrm{C}, x_{\text {est }}=16 \mathrm{~g} / \mathrm{kg}$ & $\mathbf{\square}$ & $\mathbf{\square}$ \\
\hline & & $T_{\text {reg }}=60^{\circ} \mathrm{C}, x_{\text {reg }}=16 \mathrm{~g} / \mathrm{kg}$ & & \\
\hline & Rotational speed: $15 \mathrm{rev} \mathrm{h}^{-1}$ & Rated air conditions indicated from the producer: & & \\
\hline & & Rated process air flow: $2500 \mathrm{~m}^{3} / \mathrm{h}$ & & \\
\hline & & Process/regeneration air flow: $3: 2$ & & \\
\hline & & Dehumidification capacity $4 \mathrm{~g} / \mathrm{kg}$ & & \\
\hline \multirow[t]{2}{*}{ Rotary heat exchanger } & Aluminum rotor & Rated cooling capacity: $10 \mathrm{~kW}$ & $\mathbf{\square}$ & \\
\hline & Rotational speed: $600 \mathrm{rev} \mathrm{h}^{-1}$ & Efficiency: 0.68 & & \\
\hline \multirow[t]{2}{*}{ Wet heat exchangers } & Aluminum plate cross flow & Total rated cooling capacity: $10 \mathrm{~kW}$ & & $\mathbf{\square}$ \\
\hline & $500 \times 500 \times 600$ & Dry efficiency: 0.6 & & \\
\hline Return humidifier & Packaged humidifier & Efficiency: 0.83 & $\mathbf{\square}$ & \\
\hline \multirow[t]{2}{*}{ Cooling coils } & Conventional cross flow cooling coil & $\mathrm{CC} 1: 16 \mathrm{~kW}$ & $\overline{\mathbf{a}}$ & $\mathbf{\square}$ \\
\hline & & CC2: 6 kW (only sensible cooling) & & \\
\hline \multirow{2}{*}{ Heating coils } & Conventional cross flow cooling coil & HC1: 6 kW (refrigerant cycle) & घ & $\mathbf{\square}$ \\
\hline & & HC2: 12.5 kW (solar cycle) & & \\
\hline \multirow[t]{2}{*}{ Fan 1} & Variable air flow rate & Rated air flow rate: $1250 \mathrm{~m}^{3} / \mathrm{h}$ & $\mathbf{\square}$ & $\mathbf{\square}$ \\
\hline & & $P_{\mathrm{el}}=660 \mathrm{~W}$ & & \\
\hline \multirow[t]{2}{*}{ Fan 2} & Variable air flow rate & Rated air flow rate: $1250 \mathrm{~m}^{3} / \mathrm{h}$ & $\mathbf{\square}$ & $\mathbf{\square}$ \\
\hline & & $P_{\mathrm{el}}=820 \mathrm{~W}$ & & \\
\hline \multirow{2}{*}{ Fan 3} & Variable air flow rate & Nominal air flow rate: $1250 \mathrm{~m}^{3} / \mathrm{h}$ & & a \\
\hline & & $P_{\mathrm{el}}=420 \mathrm{~W}$ & & \\
\hline \multicolumn{5}{|l|}{ Solar system } \\
\hline Flat plate solar collectors & Selective surface middle performance class & Absorber surface $22.5 \mathrm{~m}^{2}$ azimuth: $0^{\circ}$, tilt $34^{\circ}$ & $\mathbf{\square}$ & $\mathbf{\square}$ \\
\hline Heat storage & Global heat transfer coefficient $2 \mathrm{~W} / \mathrm{m}^{2} \mathrm{~K}$ & Capacity: 6501 & $\mathbf{\square}$ & $\mathbf{\square}$ \\
\hline \multicolumn{5}{|c|}{ Auxiliary chiller/auxiliary heater } \\
\hline \multirow[t]{2}{*}{ Water chiller } & (Evaporating unit) with external condenser & Rated cooling capacity $24.3 \mathrm{~kW}$ & $\mathbf{\square}$ & $\mathbf{\square}$ \\
\hline & On-off control & COP 3.47 & & \\
\hline Auxiliary gas heater & Fuel: methane gas & Rated heating power: $24 \mathrm{~kW}$ & $\mathbf{\square}$ & $\mathbf{\square}$ \\
\hline
\end{tabular}

In Fig. 6, a picture of the AHU equipped with the wet heat exchangers is shown.

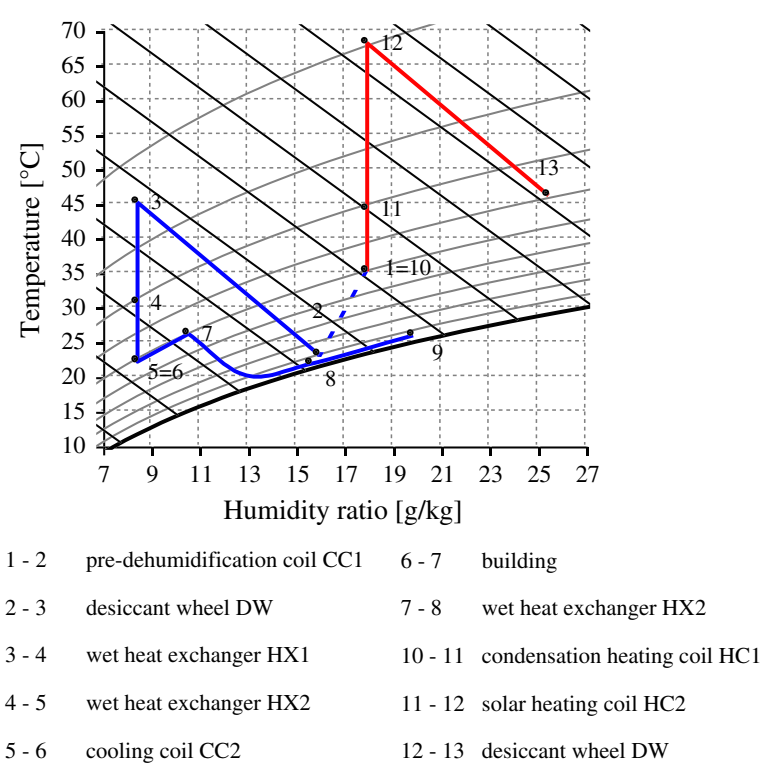

Fig. 5. Sequence of air handling on return and supply air stream for typical summer conditions on the psychrometric chart.
In addition, the control strategy of the system was updated. The first task of the control strategy is to set the seasonal operation (cooling, heating or ventilation cycles) according to the outside temperature. If the outside temperature is lower than $18{ }^{\circ} \mathrm{C}$, the seasonal mode is set to heating mode, whereas it is set to the cooling mode if the outdoor temperature is higher than $24^{\circ} \mathrm{C}$. Between these thresholds, the control strategy is set to the ventilation mode, where the fans run but no active air handling occurs.

The controlled variables used to change the operation MODE are the inside temperature and relative humidity, which is also used as feedback to control the dehumidification coil CC1. The control algorithm of the AHU for the cooling cycle has three operation modes:

MODE 1 (indirect evaporative cooling). Only indirect evaporative cooling is performed, using wet heat exchangers HX1 and HX2. The supply air intake is lateral, downstream of the desiccant wheel DW.

MODE 2 (desiccant cooling). In the solar desiccant cooling cycle, the desiccant wheel is regenerated by means of the heat provided by solar collectors ( $\mathrm{HC} 2$ ) and by the condensation heat of the refrigerant of the chiller ( $\mathrm{HC} 1)$. There is no special control of the heating power of this last coil; it only depends on the internal control of the chiller. 

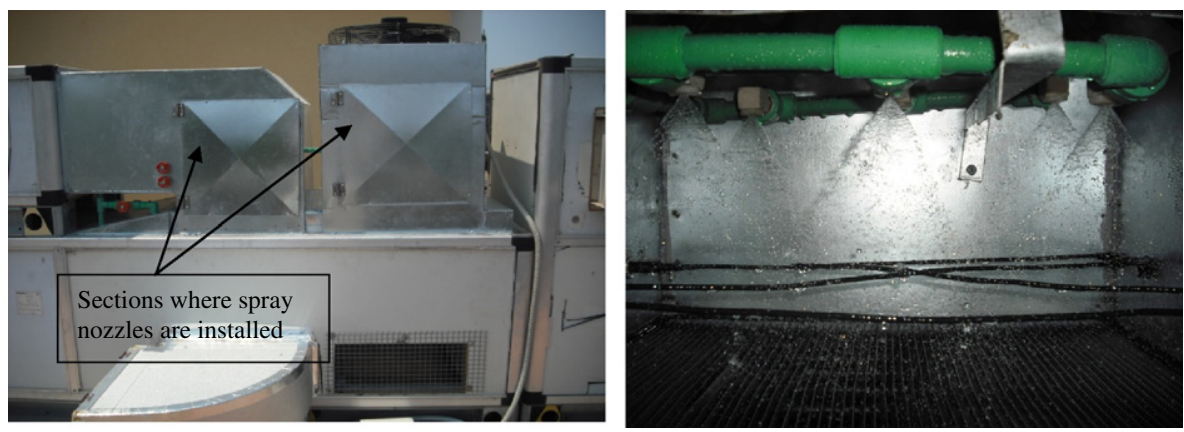

Fig. 6. AHU after the modifications done (left) - spray nozzles system used to humidify the secondary air flow in the wet heat exchangers (right).

Because this machine provides cooling not only to the auxiliary cooling coils but also to the radiant ceiling, which has its own control, condensation heat is often available.

The ratio between the process and regeneration airflows in the desiccant wheel can be varied through the speed control system for the regeneration fan. No direct control of the dehumidification capacity of the desiccant wheel is performed by varying the regeneration temperature, which is always as high as possible.

MODE 3 (aux cooling). The auxiliary backup coils $\mathrm{CC} 1$ and $\mathrm{CC} 2$ are both activated to meet the cooling loads when the desiccant cycle is not able to reach the desired indoor air conditions. The first coil, CC1, is activated and controlled to maintain a room humidity ratio of $10.5 \mathrm{~g} / \mathrm{kg}$, corresponding to a relative humidity of $50 \%$ at $26^{\circ} \mathrm{C}$. The second coil, $\mathrm{CC} 2$, is activated and controlled to reach a desired supply air temperature of $20^{\circ} \mathrm{C}$. The set point chosen for the supply temperature is quite low due to the limited cooling power of the chilled ceiling, which normally cannot meet the entire sensible cooling load of the building.

The control of the AHU for the heating cycle has two additional operation modes:

MODE-1 (heat recovery). Heat recovery from the return air is accomplished using sensible heat exchangers HX 1 and HX 2. The supply air intake is lateral, downstream of the desiccant wheel.

MODE-2 (active heating). In addition to the heat recovery process, the coil $\mathrm{CC} 2$ is used as a heating coil to provide heat from the storage to the supply air stream. A set point of $30^{\circ} \mathrm{C}$ for the supply temperature is used. A gas boiler is used as a back-up source in the winter season if the required temperature in the storage cannot be achieved by the solar collectors (set point $34^{\circ} \mathrm{C}$ ).

Fig. 7 shows a scheme of the operation modes of the control strategy.

The new control strategy is similar to the one used in the previous system configuration but differs from it in the following ways:

- The regeneration fan can be now controlled independently of the fan for the process air and can be switched off in ventilation mode $(\mathrm{MODE}=0)$ and indirect evaporative cooling mode $(\mathrm{MODE}=1)$.
- The new recirculation pump used in the wet heat exchangers is activated in MODES 2 and 3 and is off in all other operation modes.

- No air by-pass across the desiccant wheel is used.

- In the heating operation, free ventilation cannot be used because, in MODE 0, the influence of the heat exchanger cannot be excluded.

\section{Experimental results}

Monitoring data of the modified DEC system were collected during August-September 2010 and June-July 2011 and results are shown both in terms of instantaneous and seasonal energy performances. Monitoring and data acquisition started after a start-up and tuning phase that permitted the testing of the operation of the wet heat exchangers separately from the rest of the system.

In order to measure temperatures inside the $\mathrm{AHU}$, PT100 class-A sensors were used (accuracy $\pm 0.15^{\circ} \mathrm{C}$ ). For measurements of air humidity, temperature-humidity transmitters with an accuracy of $0.3{ }^{\circ} \mathrm{C} / \pm 2.5 \%$ were used. In the air ducts, temperature, relative humidity and air speed transmitters (active hotwire) were used, with an accuracy of $0.2 \mathrm{~m} / \mathrm{s}+3 \%$ of measured value, which also allowed to calculate supply and return air mass flow rates.

In the hydraulic loop, temperatures were measured with PT 100 sensors with accuracy of $\pm 0.15^{\circ} \mathrm{C}$. Ultrasonic flow meters with $2.5 \%$ accuracy were chosen for hot-water loops (solar and boiler circuit), and axial turbine-flow sensors (accuracy 3\%) were installed in the circuits of the chiller, auxiliary boiler and radiant ceiling. Solar radiation was measured using a pyranometer (1st class, ISO 9060) installed on the collector plane.

In order to assess the deviation of the monitoring results, an error analysis has been performed. Highest expected error refers to the calculation of the instantaneous heating/cooling power of AHU which is affected by the uncertainty of the measures of volume flow rate, temperature and humidity. For typical measured figures, a maximum relative error of $8 \%$ was calculated.

In general, the monitoring data acquired showed clear improvements of the energy performances of the system. 


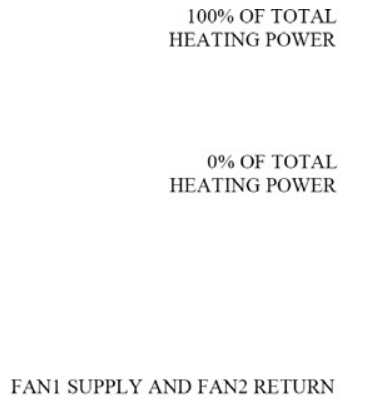

FAN3 FOR REGENERATION

RECIRCULATION PUMP FOR HX 1 AND HX2

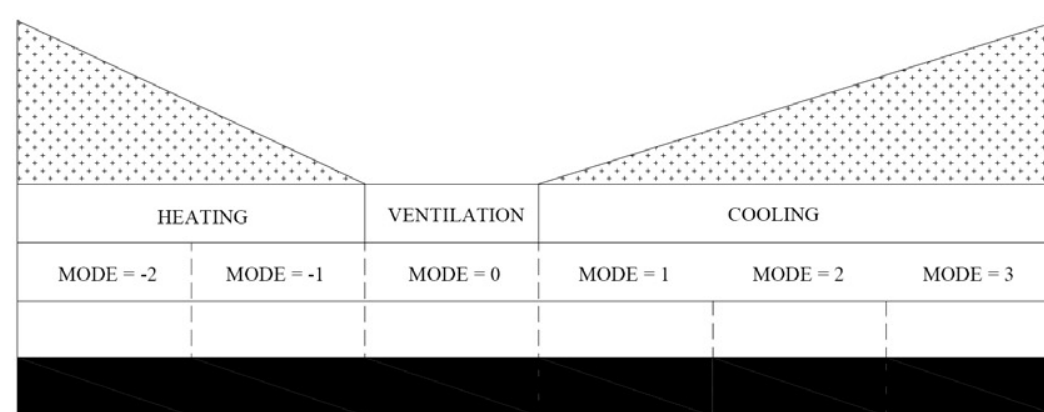

$100 \%$ OF TOTAL COOLING POWER

$0 \%$ OF TOTAL COOLING POWER

\section{RECOVERY COIL HC1
REGENERATION COIL HC2
DESICCANT WHEEL
PRE-DEHUMID. COOLING COIL CC1
SENSIBLE COOLING/HEATING COIL CC2 \\ RECOVERY COIL HC1
REGENERATION COIL HC2
DESICCANT WHEEL
PRE-DEHUMID. COOLING COIL CC1
SENSIBLE COOLING/HEATING COIL CC2 \\ RECOVERY COIL HC1
REGENERATION COIL HC2
DESICCANT WHEEL
PRE-DEHUMID. COOLING COIL CC1
SENSIBLE COOLING/HEATING COIL CC2 \\ RECOVERY COIL HC1
REGENERATION COIL HC2
DESICCANT WHEEL
PRE-DEHUMID. COOLING COIL CC1
SENSIBLE COOLING/HEATING COIL CC2 \\ RECOVERY COIL HC1
REGENERATION COIL HC2
DESICCANT WHEEL
PRE-DEHUMID. COOLING COIL CC1
SENSIBLE COOLING/HEATING COIL CC2}

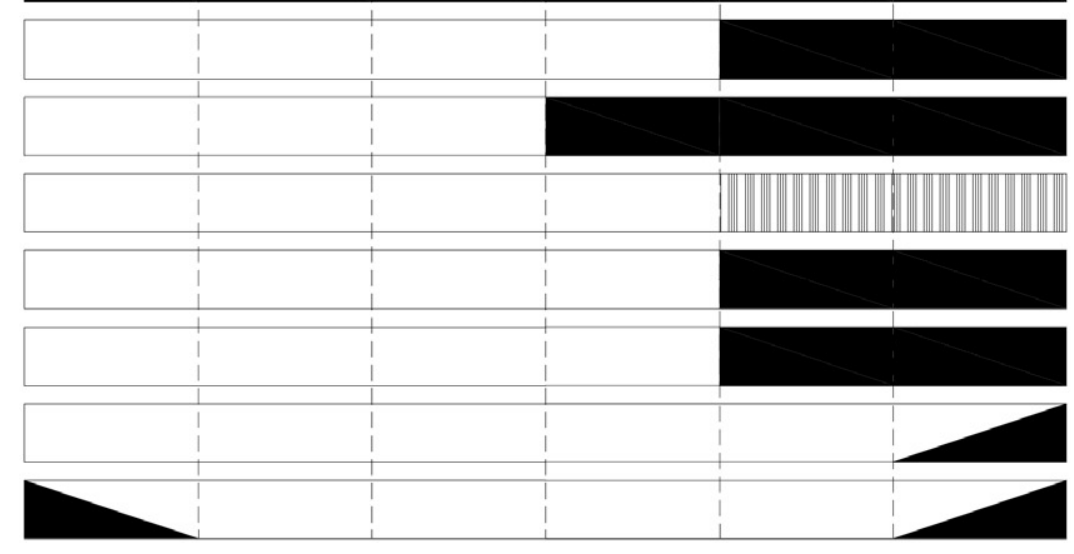

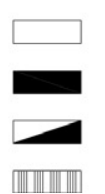

COMPONENT SWITCHED OFF

COMPONENT SWITCHED ON AT FULL POWER

COMPONENT CONTROLLED IN THE RANGE 0-100\% OF FULL POWER

COMPONENT FUNCTIONING DEPENDING BY EXTERNAL CONTROL

Fig. 7. Control strategy for the updated DEC configuration with wet heat exchangers.

In the following graphs, representative data on system operation on a daily basis are presented.

In Fig. 8, the distribution of cooling power delivered to the building is reported for an ordinary summer day, showing the very low contribution of the auxiliary cooling coils $\mathrm{CC} 1$ and $\mathrm{CC} 2$. The AHU produces dehumidification and cooling power basically only due to the DEC effect, reducing the electricity consumption for the auxiliary refrigerator used as the backup system.

The cooling power produced by the desiccant cooling cycle is calculated as the difference between the total cooling power delivered by the AHU and the contribution of both auxiliary cooling coils.

$P_{\mathrm{DEC}}=P_{\mathrm{AHU}}-P_{\mathrm{CC} 1}-P_{\mathrm{CC} 2}(\mathrm{~kW})$

For the day considered, only $1 \%$ of the total cooling energy delivered by the AHU was due to the auxiliary refrigerator.

The system can provide supply temperatures in the range of $21-22^{\circ} \mathrm{C}$, basically only due to the exploitation of the evaporative cooling potential.

It can be noted that the system can also efficiently provide air dehumidification reaching low values of supply humidity ratio when the desiccant cooling process is active (MODES 2 and 3), whereas no humidity control is operated in MODE 1. However, monitoring data registered in the conditioned space show that humidity control could be optimized for a better set point tracking.

In Fig. 9 the cooling power provided by the wet heat exchangers and the inlet and outlet temperatures are presented. In this figure, the cooling power distribution among

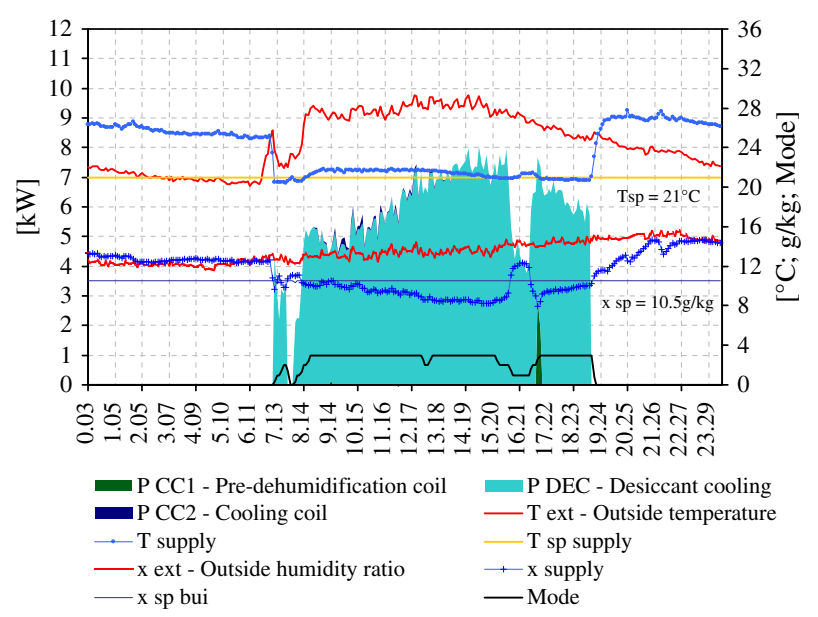

Fig. 8. Cooling power distribution in the AHU, outside and supply air conditions. 
the two heat exchangers $\mathrm{HX} 1$ and HX2 can be observed. The major contribution to the cooling of the process air is achieved by HX1 due to the high temperature difference between the process and secondary air streams entering the heat exchanger.

It is worth noting that, according to the definition of temperature ratio and efficiency, the related two curves in Fig. 10 overlap, being the supply air flow rate slightly smaller than the one on the return side. For the same day of operation, efficiency mean values of $76 \%$ and $60 \%$ result respectively for HX1 and HX2, whereas $89 \%$ is obtained if both heat exchangers are considered as one component.

Fig. 11 shows the cooling energy distribution in the AHU. Almost the total amount of the cooling energy of the AHU is related to the DEC effect, whereas the contributions of auxiliary cooling coils are close to zero.

The electrical COP of the AHU is defined as the total cooling energy delivered by the AHU divided by the electricity consumption due to fans, pumps and other auxiliaries, including the electricity consumed by the chiller for the cold production related to the cooling coils (Henning, 2004; Sparber, 2008).

$C O P_{\text {el AHU }}=\frac{P_{\mathrm{AHU}}}{P_{\text {el Fan }}+P_{\text {el pumps AHU }}+P_{\text {el cool Aux }}}(-)$

In Fig. 12 the electrical COP of the AHU for the same summer day is shown. It can be noted that, the total cooling power and the desiccant and evaporative cooling power almost overlap. Due to the increased cooling performances, the electrical COP of the system was significantly improved in comparison to the previous configuration, reaching 4.6 as the mean daily value with peaks up to 6 . Typical mean values of the previous configurations ranged from 2 to 2.9 and from 3.5 to 4.5 for the peak values (Beccali et al., 2008).

Even if an additional fan is introduced in the new system configuration, the related increase in electricity consumption is well counterbalanced by the energy savings due to the lower contribution of auxiliary cooling coils. In the

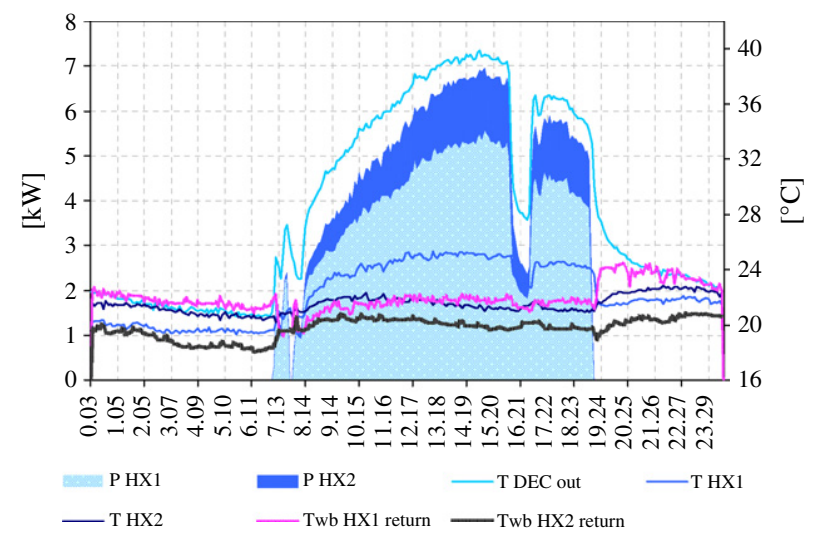

Fig. 9. Cooling power of wet heat exchangers used for the indirect evaporative cooling of the supply air.

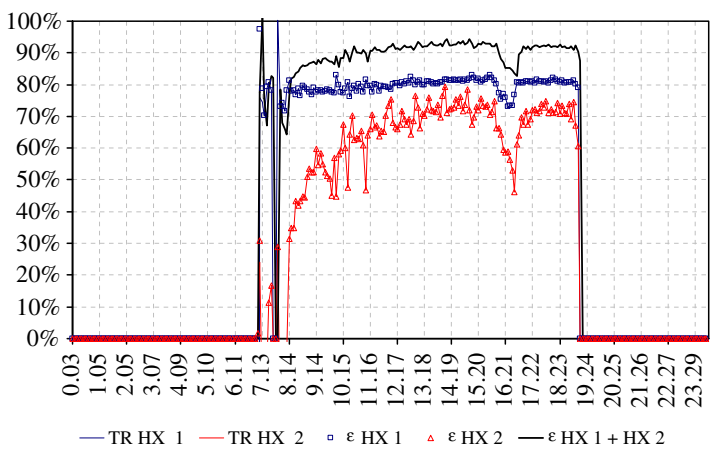

Fig. 10. Efficiency and temperature ratio of the wet heat exchangers HX1 and HX2.

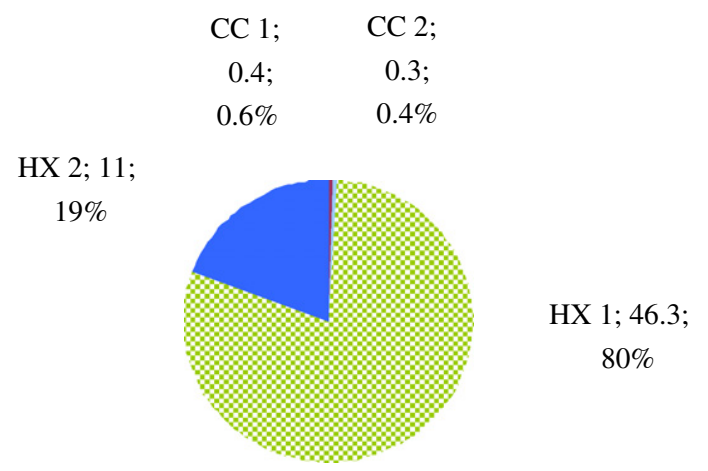

Fig. 11. Distribution of the cooling energy delivered by the AHU.

new system configuration, the fan used for the regeneration of the desiccant wheel can now be controlled independently of the one used on the process air side, permitting the optimization of operation according to the regeneration requirements.

The new configuration can also reduce the work of the fans in the winter operation, since the return humidifier was eliminated and the fan used for the regeneration can now be switched off.

For an evaluation of the heating power required for the regeneration of the desiccant wheel, the following indexes can be defined:

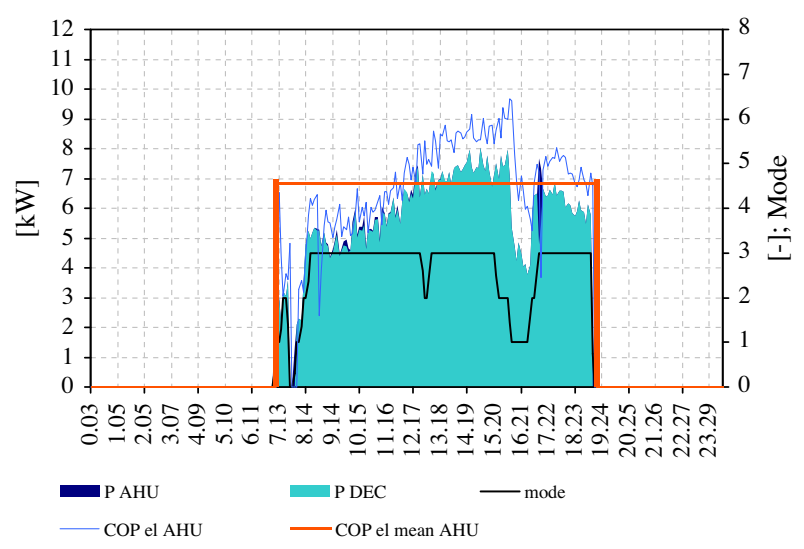

Fig. 12. Electrical COP of the AHU. 


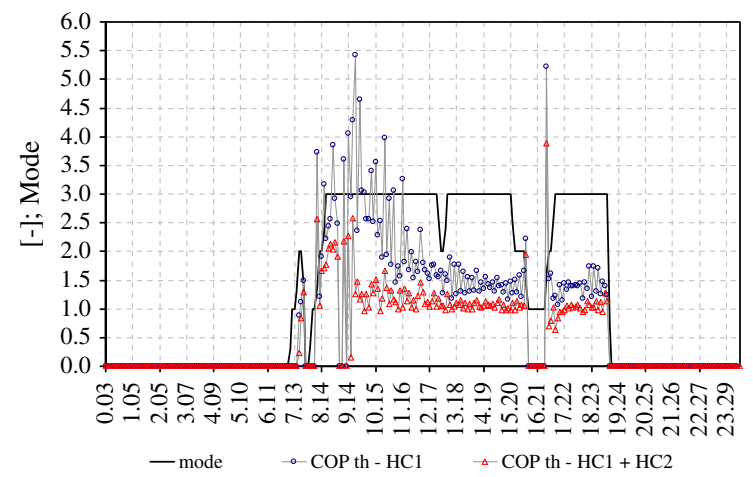

Fig. 13. Thermal COP of the AHU.

$$
\begin{aligned}
C O P_{\mathrm{th} \mathrm{HC} 2} & =\frac{P_{\mathrm{DEC}}}{P_{\mathrm{HC} 2}}(-) ; \quad C O P_{\mathrm{th} \mathrm{HC} 1+\mathrm{HC} 2} \\
& =\frac{P_{\mathrm{DEC}}}{P_{\mathrm{HC} 1}+P_{\mathrm{HC} 2}}(-)
\end{aligned}
$$

In Fig. 13, both the thermal COPs of the system referring to the solar heat $\left(\mathrm{COP}_{\text {th }} \mathrm{HC}_{2}\right)$ and to the total heat used for the regeneration $\left(\mathrm{COP}_{\text {th }} \mathrm{HC} 1+\mathrm{HC}_{2}\right)$ are presented. Daily values obtained for the thermal COP can be considered very positively even if the total amount of regeneration heat is taken into account. The mean daily value of $\mathrm{COP}_{\text {th }}$ is about 1.1 if the heat provided by both heating coils $\mathrm{HC} 1$ and $\mathrm{HC} 2$ is considered, whereas it amounts to 1.8 if only solar heat is taken into account.

Because the auxiliary cooling machine is used to feed the radiant ceiling for ambient sensible cooling, the heat recovery coil $\mathrm{HC} 1$ is often active, increasing the temperature of regeneration air flow by about $12-15^{\circ} \mathrm{C}$ and consequently assuring good thermal COP of the system.

A comparison on seasonal basis between energy performances related to the previous and new system configurations was carried out. Monitoring data presented for the previous configuration were collected during May, June 2009 and July, August, September 2008. Since the operation hours between the two cases are different amounting to 838 and 1459 respectively for the new and the previous system configuration. Therefore the analysis must be done in terms of relative values.

Fig. 14 shows the cold distribution in the AHU both for the previous and new system configuration. It can be noted that the contribution of the temperature controlling coil $\mathrm{CC} 2$ is strongly minimized. Thus, the supply temperature of the AHU in the new configuration is typically reached without any use of the cooling coil CC2.

For a better understanding of the results, meteorological conditions occurred during the two time periods considered must also be taken into account. The higher contribution of the first cooling coil CC1, registered in July 2011, was related to the higher external air humidities measured (mean value registered in 2011 was $17 \mathrm{~g} / \mathrm{kg}$ whereas $13.7 \mathrm{~g} / \mathrm{kg}$ in 2008).

However, the total contribution of the desiccant and evaporative cooling effect is about $30 \%$ higher for the new configuration $(69 \%)$ in comparison to the previous one $(53 \%)$.

Fig. 15 shows the distribution of electricity consumption due to fans, back-up chiller and auxiliaries. In particular, the electricity consumption for the cold production of the back-up chiller is lower for the new system configuration as percentage value.

The water consumption in the new DEC configuration is due to evaporation occurring on the secondary side of the wet heat exchangers HX1 and HX2 and can be calculated as the cooling energy delivered by the AHU due to the DEC process divided by the heat of vaporization of water. With the symbols introduced above and referring to the thermodynamic process described in Fig. 5, it can be estimated with the following formula:
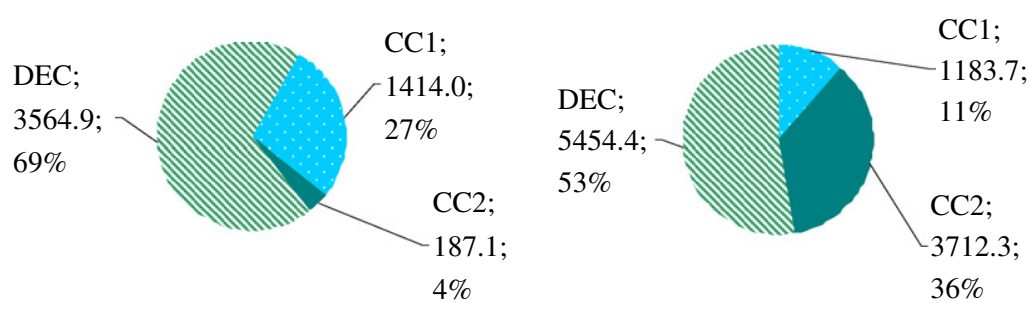

Fig. 14. Distribution of the seasonal cooling energy in $\mathrm{kWh}$ produced by the new (left) and the previous (right) DEC AHU.
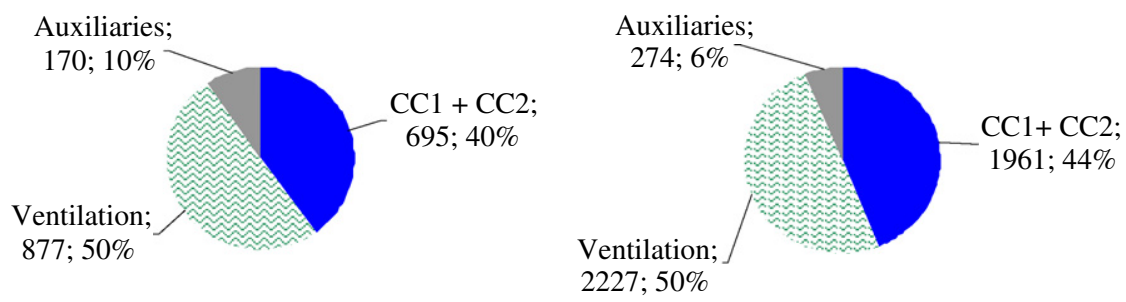

Fig. 15. Comparison of the electricity consumption distribution between the new (left) and the previous (right) system configuration [kWh and \%]. 


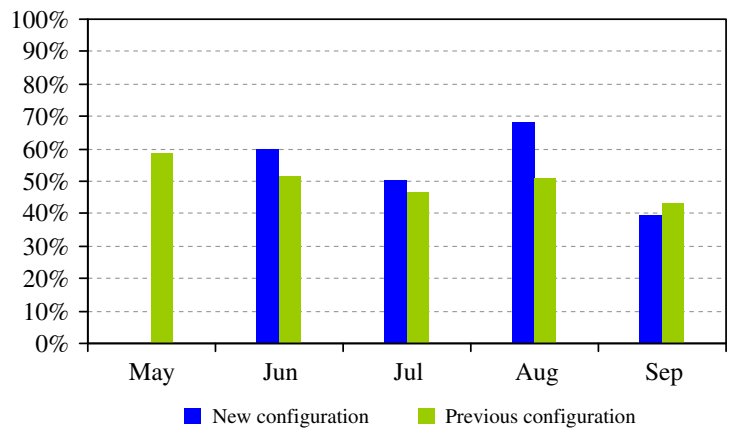

Fig. 16. Comparison of monthly PE saving between the new (left) and the previous (right) system configuration.

$$
\begin{aligned}
W C & =\frac{Q_{\mathrm{DEC}}}{r_{0}}=\frac{1}{r_{0}} \cdot \sum_{\mathrm{t}}\left[\dot{m}_{1}\left(h_{3}-h_{5}\right) \frac{1}{3600} \Delta t\right] \\
& \equiv \frac{1}{r_{0}} \cdot \sum_{\mathrm{t}}\left[\dot{m}_{2}\left(h_{9}-h_{7}\right) \frac{1}{3600} \Delta t\right](\mathrm{kg})
\end{aligned}
$$

Considering the total cooling energy produced by the DEC process amounting to $3564 \mathrm{kWh}$ and the total operation hours of the system $(838 \mathrm{~h})$, a daily mean value of water consumption of about $70 \mathrm{l} /$ day can be calculated.

Finally, a comparison between the two DEC system configurations and a conventional AHU is shown in Fig. 16. The analysis was performed according to the mentioned monitoring procedure developed in the framework of the IEA Task 38.

Monitoring results show that better performances for the new DEC configuration were experimented even if the difference between the two cases is moderate. The primary energy saving calculated as seasonal mean value results $53.7 \%$ and $49.2 \%$ respectively for the new and the previous system configuration. For a better understanding of the results, the mentioned increase of the contribution of the cooling coil $\mathrm{CC} 1$ and the weight of the ventilation and auxiliaries in the electricity consumption distribution have to be taken into account.

\section{Conclusions}

In the present work, an innovative desiccant cooling cycle using wet heat exchangers is presented. The system presented is a Solar DEC air handling unit, which was recently modified and updated according to a new concept mainly based on the use of wet plate heat exchangers.

Monitoring results related to the modified configuration showed that, due to the optimization of the indirect evaporative cooling process, a supply temperature in the range of 21$22{ }^{\circ} \mathrm{C}$ can be achieved without the use of an auxiliary cooling coil. Therefore, the electricity consumption of the auxiliary cooling machine in the new system configuration can be significantly reduced in comparison to the previous one.

Monitoring data show very good operation and high efficiency of wet plate heat exchangers.

Furthermore, the use of the plate heat exchanger eliminates the possible moisture carryover that can occur in the rotative heat exchangers normally used in DEC systems and air leakages between two airflows.

The use of a dedicated fan for the regeneration of the desiccant wheel seems to be a good solution permitting an independent control of the regeneration process. The new configuration can also reduce the work of the fans in the winter operation, since no return humidifier is used and the regeneration fan can now be switched off.

According to results shown, the modifications made have brought considerable benefits in terms of higher electrical COP and consequently primary energy saving in comparison with a conventional AHU.

The results of system performances are clearly related to the climate of the site. Better figures can be expected in dryer climates, since high values of outside air humidity ratio cause a major operation of the auxiliary refrigerator reducing the primary energy saving.

The authors are working on the efficiency assessment of wet heat exchangers through targeted experimental tests carried out in a specific facility. Numerical simulations of the whole DEC system will be utilized to evaluate performances in other climatic conditions.

\section{Acknowledgment}

The authors acknowledge the support provided by ENEA Research Institution for this research project.

\section{References}

Beccali, M., Finocchiaro, P., Luna, M., Nocke, B. 2008. Monitoring of a solar desiccant cooling system in Palermo (Italy). First results and test planning. In: Intern. Conference EUROSUN 2008, Lisbona, 7-10 October 2008, pp. 316-317, ISBN 978-972-95854-7-0 (Abstract).

Beccali, M., Finocchiaro, P., Nocke, B. 2009. Solar desiccant cooling system operating in Palermo (Italy): results and validation of simulation models. In: Proceedings of the OTTI Conference Solar Air Conditioning, Palermo, 30th September-2nd October, 2009, pp. 368375, ISBN 978-3-941758-06-9.

Bourdoukan, P., Wurtz, E., Joubert, P., 2009. Experimental investigation of a solar desiccant cooling installation. Solar Energy 83, 2059-2073.

Guo, X.C., Zhao, T.S., 1998. A parametric study of an indirect evaporative cooler. International Communications in Heat and Mass Transfer 25 (2), 217-226.

Henning, H.M., 2004. Solar-Assisted Air-Conditioning in Buildings - A Handbook for Planners. Springer Wien, New York.

Jain, S., Dhar, P.L., 1995. Evaluation of solid-desiccant-based evaporative cooling cycles for typical hot and humid climates. International Journal of Refrigeration 18 (5), 287-296.

Ren, Chengqin, Yang, Hongxing, 2006. Analytical model for the heat and mass transfer processes in indirect evaporative cooling with parallel/ counter flow configurations. International Journal of Heat and Mass Transfer 49, 617-627.

Rey Martìnez, F.J., Velasco Gómez, E., Herrero Martìn, R., Martìnez Gutiérrez, J., Varela Diez, F., 2004. Comparative study of two different evaporative systems: an indirect evaporative cooler and a semi-indirect ceramic evaporative cooler. Energy and Buildings 36, 696-708.

Rowe, D., White, S., Goldsworthy, M., Spillmann, T., Reece, R., Rossington, D., Dolly, B., Larre, M., Thomson, R., 2010. In: Preliminary Findings on the Performance of a New Residential Solar Desiccant Air-Conditioner Proceedings of EUROSUN 2010 Graz, Austria. 
Sparber, W., 2008. 240 - Unified Monitoring Procedure and Performance Assessment for Solar Assisted Heating and Cooling Systems, Eurosun 2008, Lisbon.

Sparber, W., Napolitano, A., Besana, F., Thür, A., Nocke, B., Finocchiaro, P., Bujedo Nieto, LA., Rodriguez, J., Nùňez, T., 2009. Comparative results of monitored solar assisted heating and cooling installations. In: Proc. of the 3rd Intern. Conference Solar AirConditioning, Palermo (I), 30 September-2 October.

\section{Further reading}

ASHRAE Handbook Fundamentals (SI) 2005. Atlanta, USA, American Society of Heating, Refrigeration and Air Conditioning Engineer.

Saman, W.Y., Alizadeh, S., 2002. An experimental study of a cross-flow type plate heat exchanger for dehumidification/cooling. Solar Energy $73(1), 59-71$. 